\title{
TINDAK TUTUR PENGGUNAAN BAHASA HIPNOTIS: KAJIAN PRAGMATIK
}

Indah Afrianti ${ }^{\varpi}$, Sri Asmiatiningsih ${ }^{2}$

Program Studi Pendidikan Bahasa Inggris, Stkip Yapis Dompu, Jl.Sorisakolo No.1 Dompu NTB', 84211 Program Studi Administrasi, Stisip Mbojo Bima, Kota Bima NTB², 84115

凶e-mail : indahgracilaria@gmail.com.

sriasmia@yahoo.com

\begin{abstract}
This study aims to describe speech acts using hypnotic language in terms of pragmatics by using Grice's cooperative maxims, namely maxims of quantity, maxims of quality, maxims of relevance, and maxims of implementation. The method used in this study is a qualitative method that produces descriptive data and note-taking techniques. The source of data in this study was the conversation of the hypnotized and hypnotized speakers. The data examined in the study were oral hypnotic utterances that had been transcribed in written form. The data are successively identified, classified, and described based on pragmatic theory. Techniques Data analysis is carried out using the principle of cooperation which consists of maxim of quality, maxim of quantity, maxim of relevance and maxim of implementation. The results of this study indicate that hypnotic speech uses maxim of quantity more often than other maxims. The maxim of quantity requires each participant to contribute as much or as much speech as needed by the interlocutor, this is related to the hypnosis used is the subject's subconscious so that there are imperative sentences, namely commands, then there is an if-then pattern. The subject of hypnosis: will say a sentence that he thinks there is logic in the sentence. Basically, the use of hypnotic language implements Grice's principle of cooperation between the hypnostist and the hypnotic subject.
\end{abstract}

Keywords: Pragmatics, hypnotist, grice's cooperation maxim.

\begin{abstract}
Abstrak
Penelitian ini bertujuan untuk mendeskripsikan tindak tutur penggunaan bahasa hipnotis dilihat dari sisi pragmatik dengan menggunakan maksim kerjasama Grice yaitu maksim kuantitas, maksim kualitas, maksim relevansi, dan maksim pelaksanaan. Metode yang digunakan dalam penelitian ini adalah metode kualitatif yang menghasilkan data deskriptif dan teknik simak catat. Sumber data dalam penelitian ini adalah dari percakapan penutur yang dihipnotis dan yang menghipnotis. Data yang diteliti dalam penelitian adalah tuturan-tuturan lisan bahasa hipnotis yang telah ditranskrip dalam bentuk tulisan. data tersebut secara berturut-turut diidentifikasi,diklasifikasi,dan didekripsikan berdasarkan teori pragmatik. Teknik Analisis data dilakukan dengan menggunakan prinsip kerjasama yang terdiri dari maksim kualitas, maksim kuantitas, maksim relevansi dan maksim pelaksanaan. Hasil penelitian ini menunjukkan bahwa tuturan hipnotis lebih sering menggunakan maksim kuantitas ketimbang maksim lainnya. Maksim kuantitas menghendaki setiap peserta memberikan kontribusi tuturan yang secukupnya atau sebanyak yang dibutuhkan oleh lawan bicaranya, hal ini berkaitan dengan hipnotis yang digunakan adalah dibawah sadar subjek sehingga ada kalimat imperative yaitu perintah, kemudian ada pola jika-maka. Subjek hipnotis: akan menuturkan kalimat yang dikiranya ada suatu kelogisan dalam kalimat. Pada dasarnya penggunaan bahasa hipnotis melaksanakan prinsip kerjasama Grice antara hypnostist dan subjek hipnotis.
\end{abstract}

Kata kunci: Pragmatik, hipnotis, maksim kerjasama grice 


\section{Pendahuluan}

\section{Latar Belakang}

Bahasa merupakan sebuah sarana komunikasi yang memiliki peranan penting dalam kehidupan sosial. Bloomfield (dalam Sumarsono: 2007:18) mengatakan bahwa bahasa merupakan sistem lambang bunyi yang bersifat sewenang-wenang (arbitrer) yang dipakai oleh anggota masyarakat untuk saling berhubungam dan berinteraksi. Tanpa bahasa, manusia tidak dapat berkomunikasi dan mengekspresikan pikiran serta perasaannya. Hal ini menandakan bahwa dengan adanya bahasa manusia lebih mudah berinteraksi dengan lingkungan sosialnya. Bahasa sendiri dapat dikatakan sebagai sistem lambang bunyi arbitrer yang digunakan oleh kelompok sosial untuk bekerja sama, berkomunikasi, dan mengidentifikasi diri. Pendapat ini sejalan dengan Pendapat dari Barber, Wardhaugh, Trager, de Saussure, dan Bolinger (Chaer, 2007:32) dalam Mahendra (2021).

Bahasa tidak hanya digunakan oleh para linguis saja, tetapi dari disiplin ilmu yang berbedapun bahasa kerap digunakan untuk mengkomunikasikan berbagai hal; seperti halnya politisi, psikiater, dll. Salah satu yang sedang marak diperbincangkan adalah penggunaan bahasa hipnotis, dalam hal ini bahasa sebagai medium utama yang memiliki pengaruh dengan anggapan bahwa ujaran mempunyai daya sugesti terhadap orang lain yang menjadi objek hipnotis.

Hipnotis pada umumnya terkait dengan pengenalan sebuah prosedur selama subjek tersebut disugesti untuk mengalami suatu pengalaman imajinatif. Induksi hipnotis merupakan sugesti inisial yang luas menggunakan imajinasi seseorang dan mungkin mengandung perincian lebih lanjut pada introduksinya. Sebuah prosedur hipnotis biasanya digunakan untuk memberikan dukungan dan mengevaluasi respon sugesti. Ketika menggunakan hipnotis, seseorang (subjek) dipimpin oleh orang lain (hypnotist) untuk memberikan respon terhadap sugesti untuk berubah pada pengalaman subjektifnya, perubahan persepsi, sensasi, emosi, pikiran atau tingkah laku. Orang tersebut dapat juga mempelajari hipnotis diri sendiri (self hypnosis) yang merupakan tindakan untuk mengatur prosedur hipnotis atas kemauan orang tersebut. Jika subjek merespon terhadap sugesti hipnotis, umumnya menandakan bahwa hipnotis telah berhasil dilakukan. Banyak pihak meyakini bahwa respon hipnotis dan pengalaman merupakan karakteristik keadaan hipnotis. (dalam Agus 2021)

Di dalam komunikasi seorang penutur mengartikulasikan ujaran dengan maksud untuk mengkomunikasikan sesuatu kepada lawan bicaranya, dan berharap lawan bicaranya dapat memahami apa yang hendak dikomunikasikan. Seperti yang kita tahu bahwa bahasa memiliki berbagai macam rangkaian kata, pola kalimat, fungsi, sesuai dengan kebutuhan dan waktu individu dalam menyampaikan pesan, kata yang tersusun dengan baik atau tidak, akan menimbulkan berbagai macam persepsi, perbedaan persepsi ini yang memicu timbulnya suatu konflik dalam hubungan masyarakat sosial, menjadikan hubungan yang senjang antara kaum intelektual dan kaum bias. Adanya persamaan makna akan menimbulkan suatu pengaruh yang besar bagi individu yang mendengarkan, hal ini disebut dengan sugesti yang pada akhirnya akan menimbulkan proses pemberian sugesti pada tingkat tinggi yang disebut hipnotis dengan anggapan bahwa ujaran mempunyai daya sugesti tinggi. Hipnotis dapat berguna untuk pemberian motivasi sehingga dapat mengubah pola pikir menjadi lebih baik 
atau yang disebut hipnoterapy. (Verhaar, 1996: 14).

Reality shows "Uya emang Kuya" adalah salah satu acara reality show yang tayang pada TV swasta di Indonesia. Tayangan "Uya emang Kuya" ini menarik untuk diteliti mengingat tayangan reality shows "Uya emang Kuya" adalah tayangan yang tidak mengenal batasan umur untuk disaksikan. Salah satunya tayangan tentang Hypnotis, segmen ini menggambarkan tentang trik dimana para audience di hipnotis dengan cara komedi ataupun serius sesuai dengan kondisi. Segmen ini adalah segmen yang full komedi. Adapun yang menarik untuk diteliti yaitu bagaimana tindak tutur orang yang dihipnotis karena kondisi korban tidak sadar tapi masih mampu berkomunikasi dengan baik.

\section{Tinjauan pustaka}

Penelitian yang berjudul "tipe tidak tutur dalam komunikasi dental hipnosis: suatu kajian pragmatik" ini menggunakan metode kualitatif dengan penyajian data deskriptif dengan memanfaatkan teori pragmatik. Penelitian ini bertujuan mendeskripsikan tipe tindak tutur yang digunakan dokter gigi dalam komunikasi dental hypnosis. Tipe tindak tutur yang dimanfaatkan dokter gigi dalam komunikasi dental hypnosis di dominasi oleh 1) asertif menyatakan, 2) direktifmemerintah, 3) ekspresi-memuji. Semua strategi kebahasaan yang digunakan tersebut bertujuan untuk memberi sugesti agar pasien tidak merasa kesakitan ketika dilakukan tindakan medis.

Adapun persamaan dengan peneliti terdahulu yaitu metode penelitian dan teori tindak tutur yang digunakan, sedangkan perbedaan dengan peneliti terdahulu yaitu cara menganalisis data (pasien yang berobat atau menggunakan bahasa medis) sedangkan penelitian ini menganalisis bahasa hipnotis yang tayang pada acara televisi dengan menggunakan teori maksim grice.

Berdasarkan paparan latar belakang di atas, peneliti tertarik untuk melakukan penelitian ini yang berjudul "tindak tutur penggunaan bahasa hipnotis: kajian pragmatik". Mengapa peneliti sangat tertarik untuk mengangkat judul ini karena yang meneliti tindak tutur penggunaan bahasa hipnotis masih jarang dilakukan khususnya pada tayangan "uya emang kuya" terkait tindak tutur.

\section{Rumusan Masalah}

Berdasarkan latar belakang di atas, adapun rumusan masalah dalam penelitian ini yaitu bagaimanakah tindak tutur penggunaan bahasa hipnotis?

\section{Tujuan Penelitian}

Tujuan penelitian ini, yaitu: Untuk mendeskripsikan tindak tutur dalam penggunaan bahasa hipnotis. Penelitian ini diharapkan mampu memberikan manfaat baik dari segi teoretis maupun segi praktis. Secara teoritis, penelitian ini dapat memberikan sumbangan bagi perkembangan ilmu pengetahuan berkenaan dengan kajian tindak tutur, khususnya bidang ilmu pragmatik, dan secara praktis, hasil penelitian ini dapat memberikan sumbangan pada penelitian selanjutnya khususnya dibidang ilmu kebahasaan pragmatik terkait dengan tindak tutur. Selain itu penelitian ini mampu memberikan pengetahuan tentang bentuk penggunaan bahasabahasa hipnotis.

Adapun teori yang digunakan untuk menganalisis tindak tutur penggunaan bahasa hipnotis adalah teori tindak tutur dan teori prinsip-prinsip kerja sama grice. (Leech 1993 dalam Nani dkk2014).

\section{Metode Penelitian}

Penelitian ini merupakan jenis penelitian deskriptif kualitatif dengan menggunakan pendekatan pragmatik. Menurut Sudaryanto (1993), penelitian kualitatif dengan menggunakan metode deskriptif adalah penelitian yang mengindentifikasi, mengklasifikasi, menganalisis data yang diperoleh, dan pendeskripsiannya berupa penggambaran bahasa sebagaimana adanya. Pendekatan pragmatik digunakan untuk menjelaskan 
penggunaan bahasa hipnotis dari aspek tindak tutur. Sumber data diambil dari internet dalam acara reality shows "uya emang kuya". Metode pengambilan data yang dilakukan oleh peneliti dengan cara pertama teknik simak-catat untuk mendapatkan hasil transkrip naskah percakapan bahasa hipnotis. Kedua, peneliti melakukan pencatatan (transkrip) sehingga data yang semula berwujud lisan menjadi data yang berwujud tertulis. Ketiga, data dikelompokkan sesuai dengan teori pragmatik. Dan ke-empat, peneliti menginventarisasikan data tersebut. Teknik Analisis data dilakukan dengan menggunakan prinsip kerjasama yang terdiri dari maksim kualitas, maksim kuantitas, maksim relevansi dan maksim pelaksanaan.

\section{Hasil dan Pembahasan}

\section{Pengertian Pragmatik}

Levinson (dalam Risman 2020) menyatakan bahwa pragmatik memiliki dua pengertian, pertama kajian dari hubungan antara bahasa dan konteks yang mendasari penjelasan dari pengertian bahasa. Pengertian bahasa menunjukan kepada fakta bahwa untuk mengerti suatu ungkapan atau ujaran bahasa yang diperwakilkan oleh pengetahuan diluar makna kata dan hubungannya dengan konteks pemakainya. Kedua, kajian tentang kemampuan pemakaian bahasa mengaitkan kalimat-kalimat dengan konteks-konteks yang sesuai bagi kalimat-kalimat itu.

Menurut leech (1993) dalam Nani dkk (2014, pragmatik adalah studi tentang makna dalam hubungannya dengan situasi ujar (speech situations). Pragmatik diperlukan dengan menganalisis makna yang dipertuturkan antara penutur disesuaikan dengan situari ujar.

Pragmatik juga diartikan sebagai syaratsyarat yang mengakibatkan serasitidaknya pemakaian bahasa dalam komunikasi; aspek-aspek pemakaian bahasa atau konteks luar bahasa yang memberikan sumbangan kepada makna ujaran (Kridalaksana, 1993: 177 dalam Zia 2017). Berbeda dengan pendapat Verhaar (1996: 14), pragmatik merupakan cabang ilmu linguistik yang membahas tentang apa yang termasuk struktur bahasa sebagai alat komunikasi antara penutur dan pendengar, dan sebagai pengacuan tanda-tanda bahasa pada hal-hal ekstralingual yang dibicarakan.

\section{Kalimat Imperatif}

Menurut Rahardi (2005: 79) kalimatimperatif adalah kalimat yang mengandung maksud memerintah atau meminta agar mitra tutur melakukan sesuatu sebagaimana yang diinginkan penutur. Perlu ditegaskan bahwa dalam penelitian ini istilah Kalimat Perintah dan Kalimat Suruh tidak digunakan. Jika ditinjau dari isinya, kalimat imperatif dapat dibagi menjadi enam jenis, yaitu:

1) Perintah atau suruhan biasa, yaitu jika pembicara menyuruh lawan bicaranya berbuat sesuatu.

2) Perintah halus, yaitu jika pembicara tampaknya tidak memerintah lagi, tetapi menyuruh mencoba atau mempersilakan lawan bicara berbuat sesuatu, ditandai dengan penggunaan kata tolong, coba, silakan, sudilah dan kiranya.

3) Permohonan, jika pembicara, demi kepentingannya, minta lawan bicara berbuat sesuatu, ditandai dengan penggunaan kata minta atau mohon. Subjek pelaku kalimat perintah permintaan ialah pembicara yang sering tidak dimunculkan.

4) Ajakan dan harapan, yaitu jika pembicara mengajak atau berharap lawan bicara berbuat sesuatu, ciri-ciri kalimat ini biasanya didahului dengan kata ayo (lah), mari (lah), harap dan hendaknya.

5) Larangan atau perintah negatif, jika pembicara menyuruh agar jangan dilakukan sesuatu ditandai dengan 
penggunaan kata jangan (lah). Berikut adalah contoh kalimat larangan atau perintah negatif.

6) Pembiaran, yaitu jika pembicara minta agar jangan dilarang. Yang termasuk dalam kalimat imperatif pembiaran ialah pembiaran yang dinyatakan dengan kata biar (lah) atau biarkan (lah). Kalimat ini dapat diartikan bahwa kalimat itu menyuruh membiarkan supaya sesuatu terjadi atau berlangsung. Dalam perkembangannya kemudian pembiaran berarti minta izin agar sesuatu jangan dihalangi.

\section{Tindak Tutur}

Tindak tutur (speech art) merupakan unsur pragmatik yang melibatkan pembicara, pendengar atau penulis pembaca serta yang dibicarakan. Dalam penerapannya tindak tutur digunakan oleh beberapa disiplin ilmu. Adapun pengertian tindak tutur yang dikemukakan oleh para ahli bahasa, antara lain: Austin, Searle, Chaer, dan Tarigan.

Austin (dalam Rusminto, 2010) pertama kali mengemukakan istilah tindak tutur. Austin mengemukakan bahwa aktivitas bertutur tidak hanya terbatas pada penuturan sesuatu, tetapi juga melakukan sesuatu atas dasar tuturan itu.

Mengujarkan suatu tuturan tertentu dipandang sebagai melakukan tindakan (mempengaruhi, menyuruh), di samping memang mengucapkan atau mengujar tuturan itu.

Purwo dalam Mahendra (2021) menyatakan rasionalitas ditampilkannya istilah tindak tutur adalah bahwa di dalam mengucapkan sesuatu ekspresi, pembicara tidak semata-mata mengatakan sesuatu dengan mengucapkan ekspresi itu.

Dalam mengucapkan ekspresi ia, juga menindakkan sesuatu. Menurut Austin ketika bertutur seseorang tidak hanya bertutur tapi juga melakukan sesuatu tindakan. Menurutnya ada tiga tindakan yang dapat dilakukan melalui tuturan, yaitu:

\section{a) Lokusi}

Lokusi adalah tindak mengucapkan sesuatu dengan kata, frasa dan kalimat sesuai dengan makna yang dikandung oleh kata, frasa, dan kalimat itu. Tindak tutur ini dapat disebut sebagai the act of saying something. Dalam tindak lokusi tidak dipermasalahkan maksud dan fungsi tuturan. Tuturan "Tanganku gatal!" semata-mata hanya untuk memberitahukan kepada mitra tutur bahwa pada saat itu penutur sedang dalam keadaan sakit gatal.

\section{b) Ilokusi}

Ilokusi adalah tindak tutur yang sekaligus melakukan sesuatu tindakan. Tindak tutur semacam ini dapat dikatakan sebagai the act of doing something. Pertanyaan yang diajukan berkaitan dengan tindak ilokusi adalah "Untuk apa tuturan itu dilakukan?" Tuturan "Tanganku gatal!" bukan semata-mata untuk memberitahukan kepada mitra tutur bahwa pada saat dituturkannya tuturan rasa gatal sedang menyerang. Namun lebih dari itu penutur menginginkan mitra tutur melakukan tindakan tertentu yang berkaitan dengan rasa gatal pada tangannya.

\section{c) Perlokusi}

Perlokusi adalah tuturan yang memiliki efek atau daya yang ditimbulkan dari sebuah tuturan. Efek atau daya tuturan yang dapat ditimbulkan oleh penutur secara sengaja, dapat pula secara tidak sengaja. Tindak tutur semacam ini dapat disebut dengan the act of effecting someone. Tuturan "Tanganku gatal!" bisa menimbulkan efek rasa takut pada mitra tutur, karena tuturan itu diucapkan oleh seorang tukang pukul.

\section{Prinsip-prinsip Kerja Sama Grice}

Agar pesan sampai pada mitra tutur dan komunikasi berjalan dengan baik maka para pelibat tutur selain harus memperhatikan danmempertimbangkan 
muka dari pihak mitra tutur juga harus memperhatikan prinsip-prinsip kerja sama Grace (1975), seperti berikut ini.

Maksim kuantitas dijelaskan bahwa seorang penutur diharapkan dapat memberikan pesan atau informasi yang sungguh-sungguh memadai, dirasa cukup, dan dipandang seinformatif mungkin kepada si mitra tutur, tetapi informasi atau pesan yang disampaikan tidak boleh melebihi dari informasi yang sebenarnya yang dibutuhkan oleh si mitra tutur.

Maksim Kualitas: Dengan menerapkan maksim kualitas di dalam prinsip kerja sama Grice, seorang peserta tutur diharapkan akan dapat menyampaikan sesuatu yang benar-benar nyata dan sesuai dengan fakta yang sebenarnya di dalam aktivitas bertutur sapa. Fakta tersebut harus didukung dan benar-benar didasarkan pada bukti-bukti yang jelas dan nyata.

Maksim Relevansi: Di dalam maksim relevansi dinyatakan dengan cukup jelas bahwa agar dapat terjalin kerja sama yang benar-benar baik antara penutur dan mitra tutur. Masing-masing hendaknya dapat memberikan kontribusi yang relevan tentang sesuatu yang sedang dipertuturkan itu. Bertutur dengan tidak memberikan kontribusi pada lawan tutur dianggap tidak mematuhi maksim relevansi dan dapat melanggar prinsip kerja sama Grice.

Maksim pelaksanaan: Maksim pelaksanaan di dalam prinsip kerja sama Grice mengharuskan agar setiap peserta pertuturan selalu bertutur sapa secara langsung. Secara jelas, dan isi pesan dari tuturan tersebut tidak boleh bersifat ambigu atau kabur isinya. Orang yang bertutur dengan tidak mempertimbangkan hal-hal tersebut dianggap melanggar prinsip kerja sama Grace.

\section{Data ke-1 (Tindak Tutur Percakapan Hipnotis Romy Rafael).}

Lampiran (Table 1: tindak tutur percakapan hipnotis Romy Rafael)

Lampiran (Table 2: tindak tutur percakapan hipnotis Romy Rafael)

Lampiran (Table 3: tindak tutur percakapan hipnotis Romy Rafael)

Lampiran (Table 4: tindak tutur percakapan hipnotis Romy Rafael)

\section{Data ke-2 (Tindak Tutur Penggunaan Bahasa Hipnotis Uya Kuya).}

Lampiran (Table 5: tindak tutur penggunaan bahasa Hipnotis Uya Kuya)

\section{Pola Bahasa Hipnotis}

Bahasa hipnotis memiliki pola kalimat imperatif ini berkaitan bahwa suatu bahasa memiliki keterkaitan sangat penting bagi kehidupan manusia bukan hanya sebagai objek studi tetapi yang lebih penting adalah bahasa sekurangkurangnya sebagai alat untuk mengomunikasikan berbagai hal. Bahasa sebagai medium utama dalam hipnotis sedangkan bila kita melihat pengertian hipnosis yaitu suatu kondisi mental (menurut state theory) atau diberlakukannya peran imajinatif (menurut non-state theory). Orang yang melakukan proses hipnosis memberikan sugesti terhadap subjek disebut hipnotis (hypnotist). Hipnosis biasanya disebabkan oleh prosedur yang dikenal sebagai induksi hipnosis, yang umumnya terdiri dari rangkaian panjang instruksi awal dan sugesti. Sugesti hipnosis dapat disampaikan oleh seorang hipnotis di hadapan subjek, atau mungkin dilakukan sendiri oleh subjek (Self-hipnosis). Penggunaan hipnosis untuk terapi disebut hipnoterapi, sedangkan penggunaannya sebagai bentuk hiburan bagi penonton dikenal sebagai stage hipnosis. 
Hipnotisme suatu fenomena yang menyebabkan tidur secara buatan, yang mengakibatkan sang korban secara tidak normal dapat terbuka untuk mengikuti saran/sugesti. Subjek hipnosis cenderung untuk didominasi oleh ide-ide dan saransaran dari yang menghipnotis, ketika di induksi dengan sugesti atau sesudahnya. Nugroho (2008) berpandangan bahwa hipnosis adalah suatu metode berkomunikasi baik verbal maupun nonverbal yang persuasif dan sugestif kepada seorang klien sehingga dia menjadi kreatif (berimajinasi dengan emosional dan terbuka wawasan internalnya) kemudian bereaksi (baik persetujuan maupun penolakan) sesuai dengan sistem nilai dasar spiritual yang dimiliki. Proses terjadinya hipnotis syarat hipnosis:

1) Klien/subjek (orang yang di hipnosis), harus bersedia, tidak menolak untuk di hipnosis.

2) Menggunakan bahasa yang dimengerti.

3) Hipnotist (orang yang menghipnosis) harus percaya diri.

Pola kalimat:

1) Pola sebab akibat yaitu menggunakan; jika-maka.

2) Menggunakan kalimat imperative.

3) Ada pengulangan kata yang berupa penegasan.

4)

\section{Kesimpulan}

Hasil analisis menujukkan bahwa tuturan hipnotis lebih sering menggunakan maksim kuantitas ketimbang maksim lainnya. Maksim kuantitas menghendaki setiap peserta tuturan memberikan kontribusi yang secukupnya atau sebanyak yang dibutuhkan oleh lawan bicaranya, hal ini berkaitan dengan hipnotis yang digunakan adalah dibawah sadar subjek sehingga ada kalimat imperative yaitu perintah, kemudian ada pola jika-maka. Subjek hipnotis: akan menuturkan kalimat yang dikiranya ada suatu kelogisan dalam kalimat.

\section{Ucapan Terima kasih}

Penulis megucapkan terimakasih kepada semua pihak yang sudah membantu penulis selama menempuh studi ini, baik secara langsung maupun tidak langsung. Penulis mohon maaf karena tidak menyebutkan nama satu per satu. Akan tetapi, penulis memohon semoga ALLAH S.W.T. selalu melimpahkan karunia-NYA kepada kita semua.

\section{Daftar Pustaka}

Agus Setiawan, Hypnosis \&Hypnotherapi, https://klinikhypnotherapy.wordp ress.com/2010/03/11/hipnosispengertianyang-lebih-mendalamtentang-hipnosis/. (diakses pada tanggal 18/9/2021 pukul 20:30 WIB).

Grace, H. P. (1975). 'Logic and Conversation' dalam Cole Peter dan J. Morgan (ed). Syntax and Semantics: Speech Acts. New York: Akademi Press

Mahendra, D. H. (2021) Tindak Lokusi, Ilokusi dan Perlokusi dalam Komunikasi Antar pemain Soto Madhureh. Bapala Volume 8 Nomor 05 Tahun 2021, Hlm. 918.

Darmayanti, Nani Dkk. (2014). Tipe Tindak Tutur dalam Komunikasi Dental Hipnosis: Suatu Kajian Pragmatik.Ranah,Volume 3 No.1. Nugroho, Wahjuni. (2008). Penyuluhan Kesehatan Masyarakat. Jakarta: Bahan Kuliah Untuk Mahasiswa Akper.

Rahardi, Kunjana. (2005). Pragmatik Kesantunan Imperatif Bahasa Indonesia. Jakarta: Penerbite Erlannga.

Risman, Dkk. (2020). Makna dan Fungsi Emosi Mahasiswa Kota Baubau dalam Ranah Demonstrasi. Uniqbu Journal of Social Sciences (Ujss). Halaman 25-37 
Sudaryanto. (1993). Metode dan Aneka

Teknik Analisis Bahasa:

Pengantar Penelitian Wahana

Kebudayaan secara Linguistis.

Yogyakarta: Universitas Sanata

Dharma.

Verhaar, J.W.M. (1996). Asas-asas

Linguistik Umum: Yogyakarta:

Gadjah Mada University Press.

Tajeddina, Zia, Dkk. 2017. Idealized

Native-Speaker Linguistic and

Pragmatic Norms in English as

an International Language:

Exploring the Perceptions of
Nonnative English Teachers.

Language and Intercultural

Communication.

\section{Lampiran}

\section{Data 1 (Tindak Tutur Percakapan Hipnotis Romy Rafael)}

Table 1: tindak tutur percakapan hipnotis Romy Rafael

\begin{tabular}{|l|l|}
\hline No & $\mathbf{1}$ \\
\hline Data & $\begin{array}{l}\text { (1) Romy: "Ibu Imas, saya panggil ya?" } \\
\text { (2) Ibu : "Iya" }\end{array}$ \\
\hline $\begin{array}{l}\text { Jenis Tindak } \\
\text { Tutur }\end{array}$ & Tindak Lokusi \\
\hline Jenis Maksim & Maksim Kuantitas \\
\hline $\begin{array}{l}\text { Maksim } \\
\text { Pelanggaran/Mak } \\
\text { sim Pelaksanaan }\end{array}$ & $\begin{array}{l}\text { Maksim Pelaksanaan } \\
\text { Analisis }\end{array}$ \\
$\begin{array}{l}\text { lokusi karena pada kalimat (2) ia menyatakan sesuatu. } \\
\text { Sedangkan pada percakapan tersebut menggunakan maksim } \\
\text { pelaksanaan karena pada kalimat (1) dan (2) lawan tutur suatu } \\
\text { percakapan dilaksanakan secara langsung, tidak kabur, tidak } \\
\text { paksa dan tidak berlebihan. }\end{array}$ \\
\hline
\end{tabular}

Table 2: tindak tutur percakapan hipnotis Romy Rafael

\begin{tabular}{|l|l|}
\hline No & $\mathbf{2}$ \\
\hline Data & $\begin{array}{l}\text { (3) Romy: Sekarang ibu harus percaya dengan saya ya. } \\
\text { (4) Ibu : Iya }\end{array}$ \\
\hline $\begin{array}{l}\text { Jenis Tindak } \\
\text { Tutur }\end{array}$ & Tindak Lokusi \\
\hline Jenis Maksim & Maksim Kuantitas \\
\hline $\begin{array}{l}\text { Maksim } \\
\text { Pelanggaran/Mak } \\
\text { sim Pelaksanaan }\end{array}$ & Maksim Pelaksanaan \\
\hline
\end{tabular}


Analisis Dari percakapan kalimat (3) dan (4) melaksanakan prinsip kerjasama maksim kuantitas karena kalimat (4) hanya memberikan kontribusi yang secukupnya/seperlunya saja.

Table 3: tindak tutur percakapan hipnotis Romy Rafael

\begin{tabular}{|l|l|}
\hline No & $\mathbf{3}$ \\
\hline Data & $\begin{array}{l}\text { (5) Romy: Oke, ibu lihat tangannya. Perhatikan tangannya } \\
\text { (romy mengarahkan tangan kiri si ibu kearah muka si } \\
\text { ibu). Rilex. Ikuti saya. Dan saya minta ijin sebelumnya, } \\
\text { saya memegang leher ibu. } \\
\text { (6) Ibu: Ya. }\end{array}$ \\
\hline Jenis Tindak Tutur & Tindak Lokusi \\
\hline Jenis Maksim & Maksim Kuantitas \\
\hline $\begin{array}{l}\text { Paksim } \\
\text { Pelanggaran/Maksim }\end{array}$ & Maksim Pelaksanaan \\
\hline Analisis & $\begin{array}{l}\text { Maksim kuantitas, suatu tuturan memberikan kontribusi } \\
\text { yang secukupnya atau sebanyak yang dibutuhkan oleh } \\
\text { lawan bicaranya, Romi bertanya kepada Ibu, kemudian Ibu } \\
\text { menjawab "Iya" dari percakapan ini kita bisa mengambil } \\
\text { kesimpulan bahwa penutur dan lawan tutur memberikan } \\
\text { suatu kontribusi. }\end{array}$ \\
\hline
\end{tabular}

Table 4: tindak tutur percakapan hipnotis Romy Rafael

\begin{tabular}{|c|c|}
\hline No & 4 \\
\hline Data & $\begin{array}{l}\text { (7) Romy: Ibu lihat tangannya. Fokus ke tangannya. } \\
\text { Semakin dekat. Fokus. Rileks. Semakin dekat, dekat. } \\
\text { Ibu ikuti saya. Dengarkan suara saya tapi tutup } \\
\text { matanya. Sesaat lagi saya akan menghitung dari } 1 \\
\text { sampai 3. Dihitungan ketiga, jatuhkan kepalanya ke } \\
\text { bawah dan kirimkan gelombang relaksasi ke ujung } \\
\text { kepala sampai ujung kaki. 1,2,3, bagus. Nah sekarang } \\
\text { hitung angka dari } 1 \text { sampai } 100 \text { dan masuki alam } \\
\text { relaksasi lebih dalam dari sebelumnya. Ya 1,2,3,4,5,6 } \\
\text { teruskan sendiri. Pertahankan posisi tangannya di sini } \\
\text { (posisi tangan terangkat dan berada sejajar dengan } \\
\text { kepala). Tetap tutup matanya. Sesaat lagi tangannya } \\
\text { saya lepas (romy menyentuh tangan si ibu) dan masuki } \\
\text { alam relaksasinya } 100 \text { kali lipat lebih dalam dari } \\
\text { sebelumnya. Langsung jatuhkan dan masuki alam } \\
\text { relaksasi lebih dalam dari sebelumnya. Rileks } 1,2,3 \\
\text { bagus (sambil Romy menjentikkan jarinya). Putar } \\
\text { ulang pikiran disaat ibu berhasil mencapai sesuatu. } \\
\text { Mungkin disaat ibu berhasil mencapai keinginan ibu } \\
\text { atau tujuan hidup anda. Mungkin ibu berhasil } \\
\text { mendobrak semua penghalang yang pernah ibu alami. } \\
\text { Sekarang rasakan memori tersebut menyelimuti tubuh }\end{array}$ \\
\hline
\end{tabular}




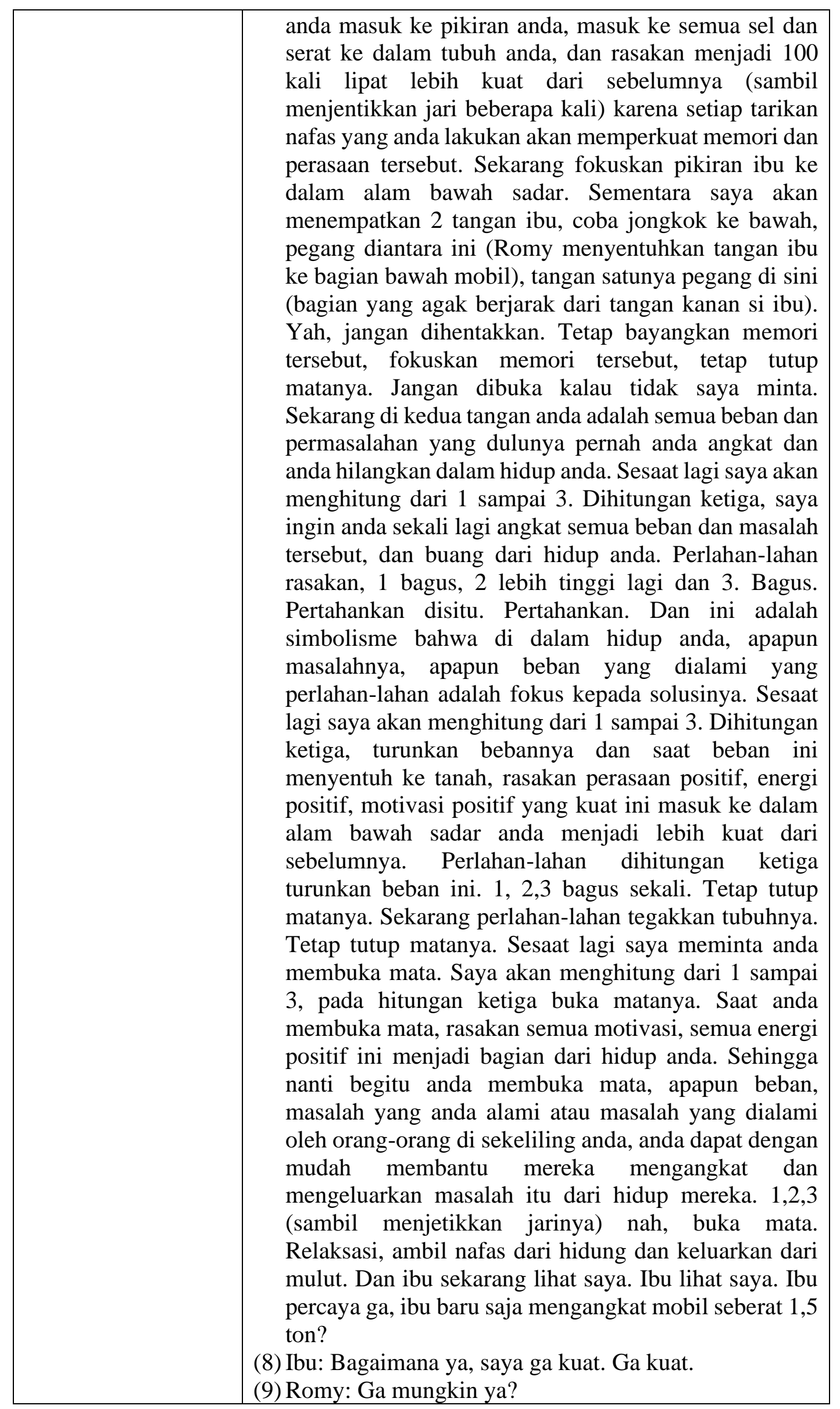




\begin{tabular}{|c|c|}
\hline & (10) Ibu: Ga mungkin, kuat. \\
\hline Jenis Tindak Tutur & Tindak Perlokusi \\
\hline Jenis Maksim & Maksim Kuantitas \\
\hline $\begin{array}{l}\text { Maksim } \\
\text { Pelanggaran/Maksim } \\
\text { Pelaksanaan }\end{array}$ & Pelanggaran Maksim Relevansi \\
\hline Analisis & $\begin{array}{l}\text { Dari percakapan tersebut termasuk pada jenis tindak tutur } \\
\text { perlokusi karena sebuah tuturan Romy mempunyai daya } \\
\text { pengaruh atau efek bagi yang mendengarkannya yaitu si } \\
\text { ibu. Ada Pelanggaran maksim relevansi dari percakapan } \\
\text { tersebut mengharuskan setiap peserta percakapan } \\
\text { memberikan kontribusi yang relevan dengan masalah } \\
\text { pembicaraan, tuturan Romy pada percakapan di atas tidak } \\
\text { relevan dengan jawaban si ibu (8) tersebut, tidak ada } \\
\text { hubungannya. Maksim kuantitas, suatu tuturan } \\
\text { memberikan kontribusi yang secukupnya atau sebanyak } \\
\text { yang dibutuhkan oleh lawan bicaranya, Romi bertanya } \\
\text { kepada Ibu, Romi berkata "Ga mungkin ya?" kemudian } \\
\text { Ibu menjawab "Ga mungkin, kuat" dari percakapan ini kita } \\
\text { bisa mengambil kesimpulan bahwa penutur dan lawan } \\
\text { tutur memberikan suatu kontribusi. Kemudian dari } \\
\text { percakapan tersebut mengandung kalimat imperatif adalah } \\
\text { kalimat yang mengandung maksud memerintah atau } \\
\text { meminta agar mitra tutur melakukan sesuatu sebagaimana } \\
\text { yang diingankan penutur, di antaranya: } \\
\text { 7. Jangan dibuka kalau tidak saya minta. Sekarang di } \\
\text { kedua tangan anda adalah semua beban dan } \\
\text { permasalahan yang dulunya pernah anda angkat dan } \\
\text { anda hilangkan dalam hidup anda. } \\
\text { 8. Sehingga nanti begitu anda membuka mata, apapun } \\
\text { beban, masalah yang anda alami atau masalah yang } \\
\text { dialami oleh orang-orang di sekeliling anda, anda dapat } \\
\text { dengan mudah membantu mereka mengangkat dan } \\
\text { mengeluarkan masalah itu dari hidup mereka. } \\
\text { 9. Sesaat lagi saya akan menghitung dari } 1 \text { sampai } 3 \text {. } \\
\text { Dihitungan ketiga, turunkan bebannya dan saat beban } \\
\text { ini menyentuh ke tanah, rasakan perasaan positif, } \\
\text { energi positif, motivasi positif yang kuat ini masuk ke } \\
\text { dalam alam bawah sadar anda menjadi lebih kuat dari } \\
\text { sebelumnya. } \\
\text { 10. Sekarang fokuskan pikiran ibu ke dalam alam bawah } \\
\text { sadar. Sementara saya akan menempatkan } 2 \text { tangan ibu, } \\
\text { coba jongkok ke bawah, pegang diantara ini (Romy } \\
\text { menyentuhkan tangan ibu ke bagian bawah mobil), } \\
\text { tangan satunya pegang di sini (bagian yang agak } \\
\text { berjarak dari tangan kanan si ibu). }\end{array}$ \\
\hline
\end{tabular}




\section{Data ke-2 tindak tutur penggunaan bahasa Hipnotis Uya Kuya}

Table 5: Tindak Tutur Penggunaan Bahasa Hipnotis Uya Kuya

\begin{tabular}{|c|c|}
\hline No & 1 \\
\hline Data & $\begin{array}{l}\text { (1) Uya: Oke, Maia Estiyanti dengarkan sugesti saya. Sekarang } \\
\text { rasakan dan bayangkan rasa gatal disekitar muka, terutama di } \\
\text { mata, di hidung, di pipi, di mulut, oke. Gatalnya sekarang } \\
\text { makin gatal lagi, jidat pun mulai gatal, dahi mulai gatal, } \\
\text { semua, kelopak mata gatal, bola mata gatal, hidung gatal, dan } \\
\text { gatalnya makin besar lagi, makin gatal oke (gue jadi ikut } \\
\text { gatal, haha). Sekarang rasa gatalnya saya hilangkan dulu. } \\
\text { Saya hilangkan dulu. Dan sekarang gatalnya ada lagi, mulai } \\
\text { ada. Oke, oke. Semakin gatal, semakin gatal, semakin gatal, } \\
\text { makin gatal, makin gatal. Oke semakin gatal. Entah kenapa } \\
\text { sekarang gatalnya hilang. Oke, dan sekarang dengarkan } \\
\text { sugesti saya yang kedua. Sugesti saya berikutnya. Kamu akan } \\
\text { merasakan gatal seperti tadi kalau kamu berbohong. Setiap } \\
\text { kali kamu melakukan sebuah kebohongan, atau setiap kali } \\
\text { kamu berbohong, maka kamu akan merasakan gatal yang } \\
\text { sangat luar biasa. Sekali lagi kalau kamu berbohong kamu } \\
\text { akan merasakan apa? Akan merasakan apa Maia? } \\
\text { (2) Maia: Gatal. } \\
\text { (3) Uya: Kamu akan merasakan gatal kalau kamu berbohong. } \\
\text { Oke, kalau kamu berbohong, seperti apa rasanya? } \\
\text { (4) Maia: Gatal. } \\
\text { (5) Uya: Oke. Gatalnya bagaimana coba? } \\
\text { (6) Maia: (Menggerakkan mulutnya ke kiri dan ke kanan) } \\
\text { (7) Uya: Kalau jujur, gimana jujur? } \\
\text { (8) Maia: (Tidak merespon apa-apa) }\end{array}$ \\
\hline $\begin{array}{ll}\text { Jenis } & \text { Tindak } \\
\text { Tutur } & \end{array}$ & Tindak tutur lokusi \\
\hline Jenis Maksim & Maksim kuantitas, maksim kualitas, maksim relevansi. \\
\hline $\begin{array}{l}\text { Maksim } \\
\text { Pelanggaran/Ma } \\
\text { ksim } \\
\text { Pelaksanaan }\end{array}$ & Maksim pelaksanaan kuantitas dan relevansi \\
\hline Analisis & $\begin{array}{l}\text { Dari data percakapan tersebut dapat merupakan data pelaksanaan } \\
\text { dari beberapa maksim yaitu maksim kuantitas dan relevansi. } \\
\text { Dari pertuturan memberikan kontribusi yang secukupnya atau } \\
\text { sebanyak yang dibutuhkan oleh lawan seperti pada kalimat (1) } \\
\text { dan (2), sedangkan maksim relevansi terdapat pada kalimat (5), } \\
(6) \text {, (7), (8) setiap tuturan tersebut memberikan kontribusi yang } \\
\text { relevan dengan masalah pembicaraan. }\end{array}$ \\
\hline
\end{tabular}

